\title{
The therapeutic potential of the novel angiotensin-converting enzyme 2 in the treatment of coronavirus disease-19
}

\author{
Ademola Adetokunbo Oyagbemi1 ${ }^{1}$, Temitayo Olabisi Ajibade ${ }^{1}$ (D) Yapo Guillaume Aboua $^{2}$ (D), \\ Idayat Titilayo Gbadamosi ${ }^{(\mathbb{D})}$, Aduragbenro Deborah A. Adedapo4 (i), Abimbola Obemisola Aro ${ }^{5}$ \\ Olumuyiwa Abiola Adejumobi6(i), Emma Thamahane-Katengua7(i), Temidayo Olutayo Omobowale (iD, \\ Olufunke Olubunmi Falayi ${ }^{9}$ (D), Taiwo Olaide Oyagbemi ${ }^{10}$ (D), Blessing Seun Ogunpolu ${ }^{8}$ (D), Fasilat Oluwakemi Hassan ${ }^{1}$ (D), \\ Iyanuoluwa Omolola Ogunmiluyi ${ }^{9}$ (D), Olufunke Eunice Ola-Davies ${ }^{1}$ (D), Adebowale Benard Saba9(iD, \\ Adeolu Alex Adedapo ${ }^{(\mathbb{D}}$, Sanah Malomile Nkadimeng ${ }^{11}$ (D), Lyndy Joy McGaw ${ }^{11} \mathbb{D}$, Prudence Ngalula Kayoka-Kabongo5 (iD, \\ Momoh Audu Yakubu12 ${ }^{12}$ and Oluwafemi Omoniyi Oguntibeju13
}

1. Department of Veterinary Physiology and Biochemistry, Faculty of Veterinary Medicine, University of Ibadan, Nigeria; 2. Department of Health Sciences, Faculty of Health and Applied Sciences, Namibia University of Science and Technology, Private Bag 13388, Namibia; 3. Department of Botany, Faculty of Science, University of Ibadan, Nigeria; 4. Department of Pharmacology and Therapeutics, University of Ibadan, Nigeria; 5. Department of Agriculture and Animal Health, College of Agriculture and Environmental Sciences, University of South Africa, Florida, South Africa; 6. Department of Veterinary Medicine, Faculty of Veterinary Medicine, University of Ibadan, Nigeria; 7. Department of Health Information Management, Botho University, Faculty of Health and Education, Botswana; 8. Department of Veterinary, Faculty of Veterinary Medicine, University of Ibadan, Nigeria; 9. Department of Veterinary Pharmacology

and Toxicology, Faculty of Veterinary Medicine, University of Ibadan, Nigeria; 10. Department of Veterinary

Parasitology and Entomology, Faculty of Veterinary Medicine, University of Ibadan, Nigeria; 11. Department of Paraclinical Science, Phytomedicine Programme, University of Pretoria, Faculty of Veterinary Science, Old Soutpan Road, Onderstepoort, 0110, South Africa; 12. Department of Environmental and Interdisciplinary Sciences, College of Science, Engineering and Technology, Vascular Biology Unit, Center for Cardiovascular Diseases, Texas Southern University, Houston, TX, USA; 13. Department of Biomedical Sciences, Phytomedicine and Phytochemistry Group, Oxidative Stress Research Centre, Faculty of Health and Wellness Sciences, Cape Peninsula University of Technology, Bellville 7535, South Africa.

Corresponding author: Oluwafemi Omoniyi Oguntibeju, e-mail: oguntibejuo@cput.ac.za

Co-authors: AAO: ademola.oyagbemi778@gmail.com, TOA: toajibade@gmail.com, YGA: yaboua@nust.na, ITG: gita4me2004@yahoo.com, ADAA: debyee1965@yahoo.co.uk,AOA: aroabimbola@yahoo.co.uk, OAA: muyenko@yahoo.com, ET: ekatengua@yahoo.co.uk, TOO: bukitayo_omobowale@yahoo.com, OOF: funkefalayi@gmail.com, TaOO: akantai2018@gmail.com, BSO: blessingpolu@gmail.com,

FOH: iamfasilathassan@gmail.com, IOO: iyanuoluwaomolola@gmail.com, OEO: ooladavies@yahoo.com, ABS: sabadee2000@gmail.com, AAA: adedapo2a@gmail.com, SMN: sanah.nkadimeng@up.ac.za,

LJM: Iyndy.mcgaw@up.ac.za,PNK: kabonpnk@unisa.ac.za, MAY: yakubu_ma@tsu.edu

Received: 06-02-2021, Accepted: 13-09-2021, Published online: 23-10-2021

doi: www.doi.org/10.14202/vetworld.2021.2705-2713 How to cite this article: Oyagbemi AA, Ajibade TO, Aboua YG, Gbadamosi IT, Adedapo ADA, Aro AO, Adejumobi OA, Thamahane-Katengua E, Omobowale TO, Falayi OO, Oyagbemi TO, Ogunpolu BS, Hassan FO, Ogunmiluyi IO, Ola-Davies OE, Saba AB, Adedapo AA, Nkadimeng SM, McGaw LJ, KayokaKabongo PN, Yakubu MA, Oguntibeju OO (2021) The therapeutic potential of the novel angiotensin-converting enzyme 2 in the treatment of coronavirus disease-19, Veterinary World, 14(10): 2705-2713.

\begin{abstract}
Severe acute respiratory syndrome coronavirus 2 (SARS-CoV-2) is the etiological agent of coronavirus disease 2019 (COVID-19). This virus has become a global pandemic with unprecedented mortality and morbidity along with attendant financial and economic crises. Furthermore, COVID-19 can easily be transmitted regardless of religion, race, sex, or status. Globally, high hospitalization rates of COVID-19 patients have been reported, and billions of dollars have been spent to contain the pandemic. Angiotensin-converting enzyme (ACE) 2 is a receptor of SARS-CoV-2, which has a significant role in the entry of the virus into the host cell. ACE2 is highly expressed in the type II alveolar cells of the lungs, upper esophagus, stratified epithelial cells, and other tissues in the body. The diminished expressions of ACE2 have been associated with hypertension, arteriosclerosis, heart failure, chronic kidney disease, and immune system dysregulation. Overall, the potential drug candidates that could serve as ACE2 activators or enhance the expression of ACE2 in a disease state, such as COVID-19, hold considerable promise in mitigating the COVID-19 pandemic. This study reviews the therapeutic potential and pharmacological benefits of the novel ACE2 in the management of COVID-19 using search engines, such as Google, Scopus, PubMed, and PubMed Central.
\end{abstract}

Keywords: Renin-angiotensin system, COVID-19, hypertension, lung injury, ACE2; SARS-CoV-2.

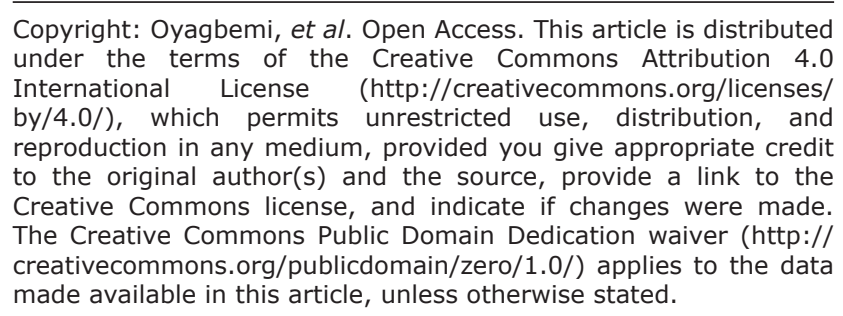

Copyright: Oyagbemi, et al. Open Access. This article is distributed under the terms of the Creative Commons Attribution 4.0 International License (http://creativecommons.org/licenses/ by/4.0/), which permits unrestricted use, distribution, and reproduction in any medium, provided you give appropriate credit to the original author(s) and the source, provide a link to the Creative Commons license, and indicate if changes were made. The Creative Commons Public Domain Dedication waiver (http:// creativecommons.org/publicdomain/zero/1.0/) applies to the data made available in this article, unless otherwise stated.

\section{Introduction}

Severe acute respiratory syndrome coronavirus (SARS-CoV-2) is the etiological agent for coronavirus disease 2019 (COVID-19). The virus was first detected in Wuhan, China, in December 2019 and was later declared by the WHO as a global pandemic in March 11, 2020. SARS-CoV-2 is a highly infectious 
virus with an extremely high degree of transmissibility. Globally, as of June 20, 2021, 177,108,695 cases of COVID-19 have been confirmed, including 3,840,223 deaths. Currently, in Nigeria, more than 167,206 cases with over 2117 deaths due to COVID-19 were reported. However, a total number of 163,550 patients have recovered.

In the past few weeks, significant achievements have been recorded in vaccine production technology. Fortunately, vaccines from Pfizer and BioNTech (USA/Germany), Moderna (USA), Johnson and Johnson (USA), AstraZeneca, (UK), Sinovac (China), and Sputnik V (Russia) have received emergency authorization for use in the UK, the USA, France, China, Africa, and other countries in the world.

However, the emergence of a new variant of SARS-CoV-2 has put the world in an unprecedented vicarious state. As of June 20, 2021, more than 2.59 billion vaccine doses have been administered worldwide. Therefore, this review aims to investigate the therapeutic potential of the novel angiotensin-converting enzyme 2 (ACE2) in the fight against the global COVID-19 pandemic.

\section{Renin-angiotensin System (RAS) and Novel ACE2}

Angiotensinogen (AGT) is a hepatic $\alpha$-2-globulin cleaved by renal renin to produce angiotensin (Ang) I, a precursor of the active peptide of the RAS (Figures-1 and 2). Unlike AGT which has 452 amino acids, angiotensin I is a decapeptide. The proteolytic action of the ACE produces angiotensin II from its precursor molecule angiotensin I. Ang II mediates its action through the modulation of angiotensin 1 (AT1R) and (AT2R) 2 receptors, respectively (Figure-1). AGT, along with other biological molecules of the renin-angiotensin-aldosterone system, tightly regulates the blood volume and pressure in the mammalian cardiovascular system by altering the physiological activities of the kidneys, lungs, blood vessels, and brain $[1,2]$. AT1 has two functional receptors, AT1a and AT1b, which are structurally similar but functionally different in their distribution in various tissues and organs $[3,4]$. In contrast to the AT2 receptor that is only present in utero, the AT1a receptor is believed to mediate several physiological and pharmacological effects postnatally [5] (Figure-2).

The potential therapeutic usefulness of zinc-dependent metalloproteinase ACE2 in the management of cardiovascular diseases and SARS has been well documented [6,7]. ACE2 is also an important modulator of the intestinal and renal absorption of protein. ACE2 is a glycoprotein with extracellular (catalytic metallopeptidase) domain and an intracellular carboxyl terminus tail. The extracellular portion shares a structural similarity with collectrin, which is responsible for the carboxypeptidase activity of ACE2. The controlling effect of the RAS under physiological condition is primarily associated with the activation of ACE and formation of angiotensin II, with the consequent induction of generalized vascular constriction throughout the cardiovascular system $[8,9]$. As a result, blood pressure is prevented from falling below the physiological range for adequate tissue perfusion. Therefore, the activity of this system is negatively regulated by ACE2, with the subsequent homeostasis of angiotensin II [10].

Chromosome Xp22 has been shown to house the ACE2 gene, which encodes the ACE2 protein comprising 805 amino acids in humans [11]. The activation of RAS mainly by the derangement of the normal cardiovascular function, such as hypovolemia and/or generalized vasodilation, leads to the production of angiotensin II from AGT in a chain reaction involving renin and ACE [12]. On the other hand, the heptapeptide Ang III with similar biological activity

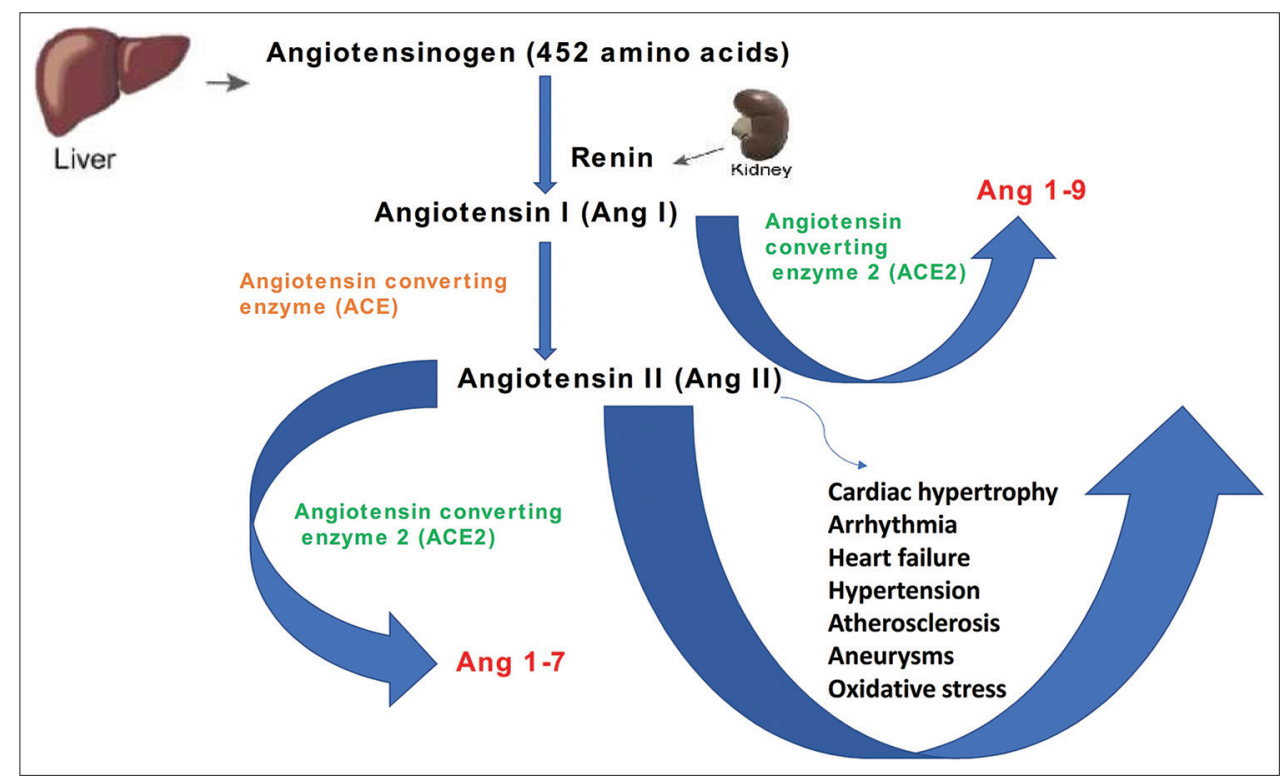

Figure-1: The components of renin-angiotensin system (RAS) and its involvement in the cardiovascular system. 


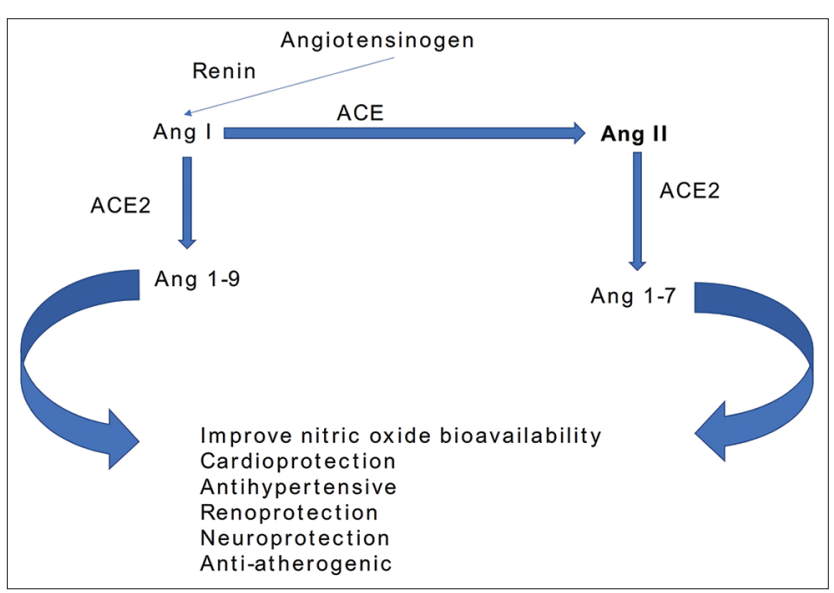

Figure-2: Catabolism of angiotensinogen and the catabolic products of novel angiotensin-converting enzyme 2.

was discovered following the removal of aminoterminal aspartate from Ang II [12]. Similarly, Ang 1-7 were formed by the removal of amino acid phenylalanine from Ang II $[13,14]$. In contrast to ACE, which removes a dipeptide from the $\mathrm{C}$ termini of substrates, ACE2 removes one amino acid, thereby degrading Ang II with the consequent formation of the nonapeptide Ang 1-9 (Figures-1 and 2). Considering these observations, ACE2 was found to convert the Ang II actions to those of Ang 1-7, including vasodilatory, antifibrotic, anti-inflammatory, and cardioprotective effects $[15,16]$. The alterations in the ACE2 level have been implicated in the pathogenesis and organ-specific pathological observations of the cardiac, renal, and respiratory tissues, as exemplified by the current COVID-19 pandemic [17]. Recently, a prominent pathological role was reported for ACE2 in the transmission of SARS coronavirus, wherein ACE2 not only acts as a receptor but is also important for viral entry [18].

\section{ACE2 and MAS1 Proto-oncogene}

The Mas receptor was first reported as a proto-oncogene that is highly expressed in the renal, adrenal, and vascular tissues [19]. However, Ang 1-7, the physiological ligand for Mas receptor, act as a vasodepressor through the reduction of peripheral resistance, thus inducing a clinically significant reduction in the blood pressure parameters [20]. A positive modulatory role of ACE 2 and Ang 1-7 in fetal development has been reported, with the reduced expression of Ang 1-7 being associated with higher cardiometabolic risk and the precipitation of non-cancerous prostatic hyperplasia in adulthood [21]. Furthermore, the non-canonical pathway of ACE2, Mas, and Ang 1-7 is known to increase the vessel diameter in the presence of cellular proliferation and growth inhibition while exerting cardiorenal protective activity [22,23].

Likewise, Prestes et al. [24] suggested the positive modulation of fibrotic tissue development by ACE2 and Mas in vitro (Figure-3), while Ang 1-7 have been implicated in several diseases associated with cardiac and vascular derangements. Durand et al. [25] reported the opposing effect of Ang 1-7 as a vasodilator mediated by Mas and Ang II (potent vasoconstrictor). Based on these findings, we hypothesize that the upregulation of ACE2/Ang 1-7/Mas signaling could offer remarkable therapeutic benefits to COVID-19 patients with severe underlying medical conditions, which may potentially reduce morbidity and mortality among infected individuals.

\section{ACE2 as a SARS-coronavirus Receptor}

The current COVID-19 pandemic has drawn much attention in the past few months. Interestingly, in 2003, its predecessor, SARS-CoV, was reported to exhibit a predilection of ACE2 in in vitro and in vivo studies [26] and the successful binding of the virus to ACE2 for subsequent host cell infection. SARS$\mathrm{CoV}$ in the host cell caused the downregulation of ACE2 and an increase in the local production of Ang II [27] (Figures-4 and 5). Thus far, only two coronaviruses, SARS-CoV and HCoV-NL63, require ACE2 for successful transmission [28]. The spike (S) protein of SARS-CoV-2 plays a significant key role in the receptor recognition and cell membrane fusion process. It is composed of two subunits, namely, S1 and $\mathrm{S} 2$. The $\mathrm{S} 1$ subunit contains a receptor-binding domain that recognizes and binds to the host receptor ACE2, while the S2 subunit mediates the viral cell membrane fusion into the host cell. The total length of SARS-CoV-2 is 1273 amino acids and consists of a signal peptide (amino acids 1-13) which is located at the N-terminus, whereas the $\mathrm{S} 1$ subunit and the S2 subunit contain 14-685 and 686-1273 amino acid residues, respectively.

\section{Tissue Distribution of ACE2 in Health and Disease}

The ACE2 enriched organs, such as the kidneys, heart, lungs, and testis, are highly susceptible to infections, while the liver, intestine, and other organs containing less abundance of ACE2 are less susceptible.

\section{ACE2 and the Lungs}

The lungs are rich in ACE2 and are highly susceptible to SARS-CoV-2 infection. Most infected patients develop pneumonia, as revealed by computerized tomography scan [29]. In fact, the lungs account for more than three quarters of ACE2 in the mammalian tissues [30]. Growing evidence has shown that in addition to respiratory distress, the derangement of the physiological function of the heart and/or kidneys often complicates disease management [31]. Moreover, the broad distribution of SARS-CoV-2 in humans is highly consistent with the pattern of ACE2 distribution [32]. Therefore, lung injury could negate pulmonary ACE2 and disrupts the Ang (1-7) ratio in favor of Ang II with the consequent exacerbation of the pathological process associated with edema in the lungs [33]. 


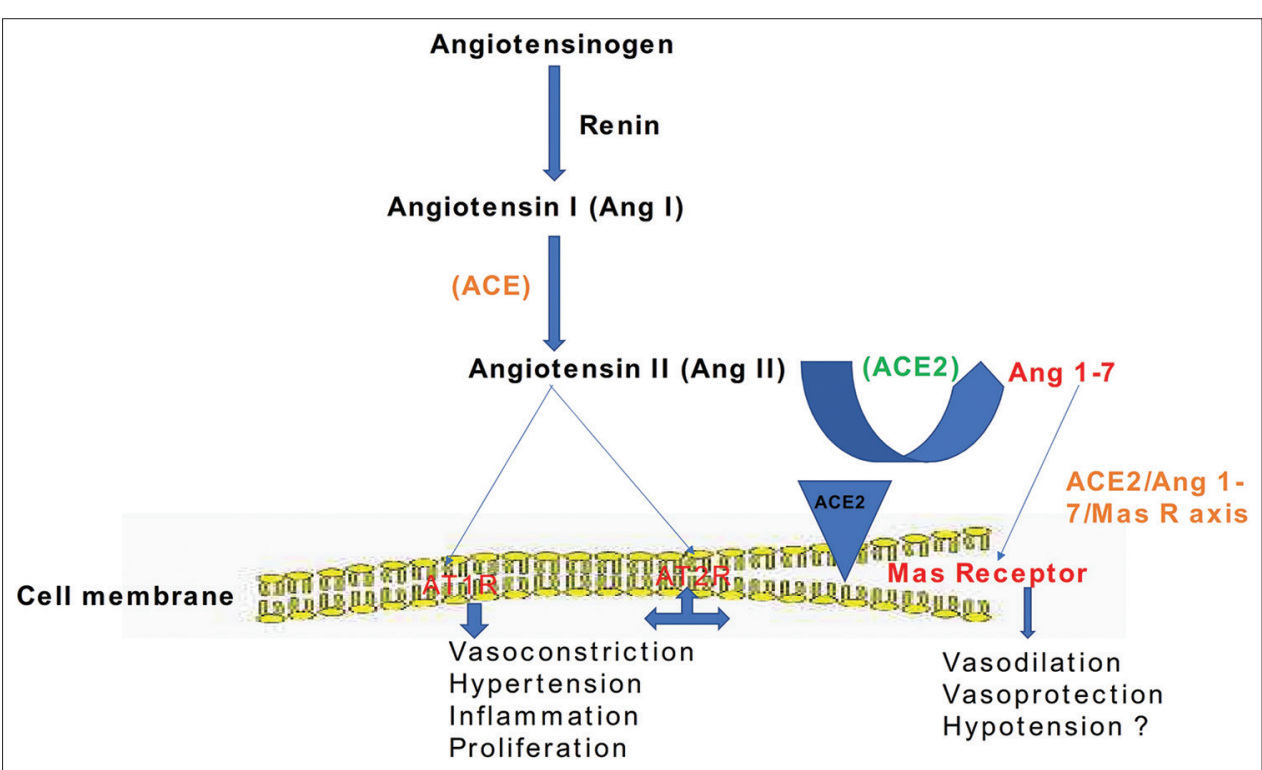

Figure-3: The potential benefits of angiotensin-converting enzyme 2/angiotensin-(1-7)/Mas axis and the implications of angiotensin type 1 receptor (AT1R).

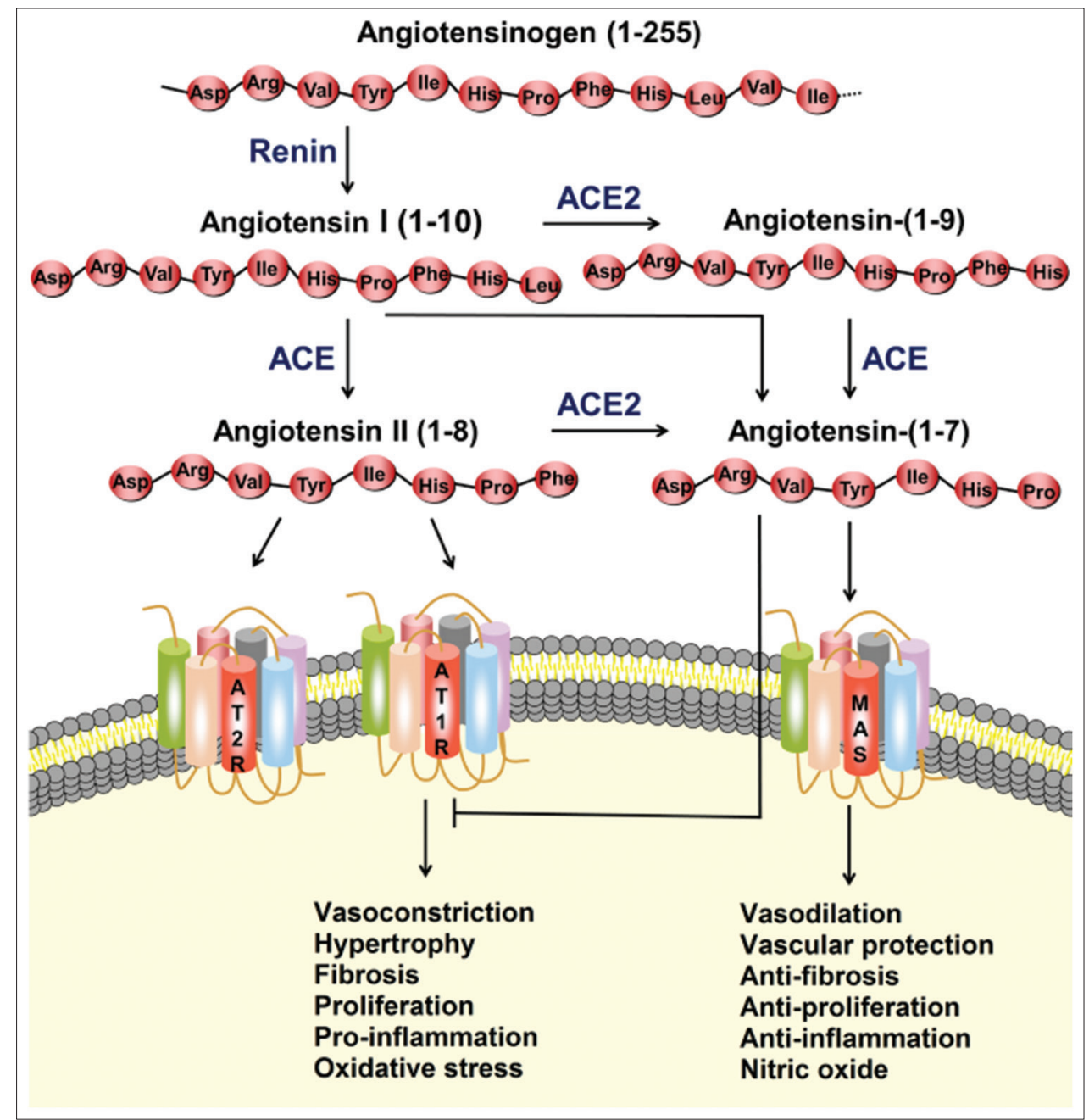

Figure-4: The structure of SARS-CoV-2 with different cell surface membrane proteins.

\section{ACE2 and Disease Conditions}

ACE2, heart failure, and coronary heart disease

Apart from the high mortality arising from severe respiratory distress associated with the COVID19 pandemic, comorbidities from heart and brain dysfunctions have been reported [34]. The heart has been found to be enriched with ACE2 proteins [35], suggesting that the cardiac muscles tend to be highly susceptible to SARS-CoV-2 infection, while a preexisting heart disease before infection may predispose 
the affected COVID-19 patients to poor disease outcome [36]. Moreover, the physiological function of the lungs is severely compromised in COVID-19 patients and is worsened by preexisting cardiac complications [37]. Hence, the loss of ACE2 function is probably associated with cardiac dysfunctions in hospitalized patients [38]. Endothelial dysfunction, heart failure, arrhythmia, and immune system dysregulation as hypothetical pathological mechanisms through ACE2 receptor modulation in COVID-19 patients have been reported [39] (Figure-6).

\section{ACE2 and Hypertension}

RAS dysregulation has been reported as the primary causal factor of the pathophysiology, pathogenesis, and poor prognosis of hypertension [40]. ACE2 has been shown to decrease the intravascular pressure under an experimental hypertensive condition [10]. Therefore, ACE2 could offer protection to the lungs and heart against injuries, indicating an obliteration of ACE2 protection in COVID-19 patients, along with

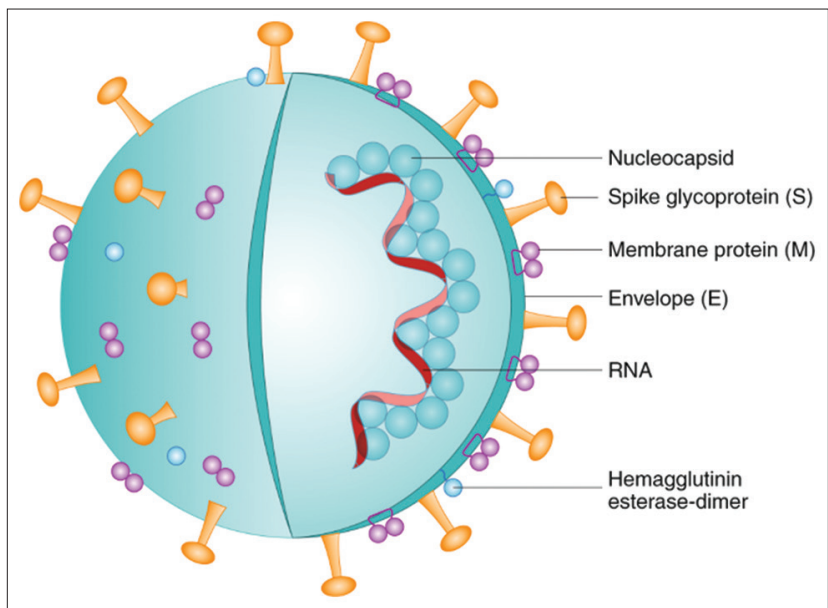

Figure-5: The structure of SARS-CoV-2 with different cell surface membrane proteins and the attachment of spike protein of SARS-CoV-2 with the receptor angiotensinconverting enzyme.

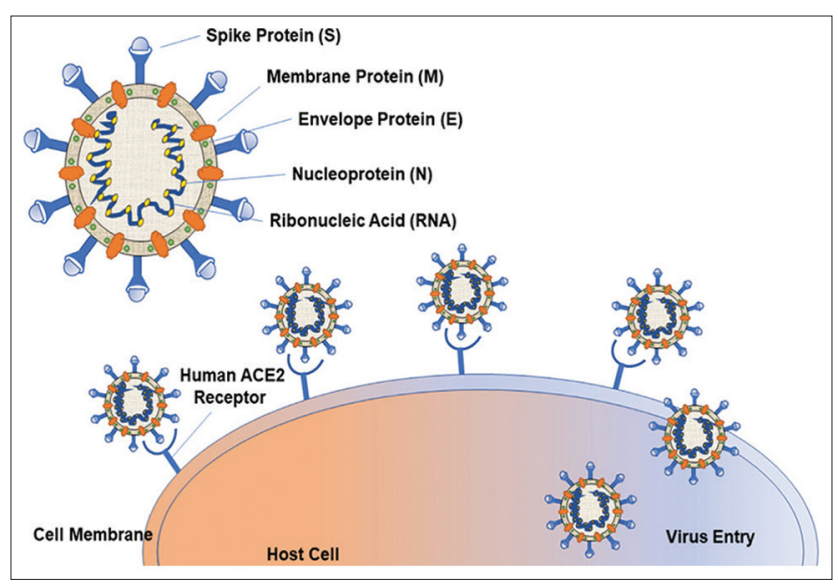

Figure-6: Cardiovascular involvement in coronavirus disease-19, key manifestations and hypothetical mechanisms. SARS-CoV-2 anchors on transmembrane angiotensin-converting enzyme 2 to enter the host cells leading to inflammation and organ failure. the concomitant development of cardiovascular complications and the loss of renal function, especially in hospitalized patients [41]. The loss of ACE2 expression has been found to increase significantly in hypertension, diabetes, nephrectomy, and the lungs of patients with idiopathic pulmonary hypertension [42]. This shows that COVID-19 patients are more predisposed to renal complications and fibrosis due to the loss of ACE2 function [43]. Therefore, a treatment regimen that will enhance the expression of renal ACE2 might contribute significantly to non-fatal disease outcomes in COVID-19 hospitalized cases. Previously, a comparative study by Yamazato et al. [44] found that lentiviral vector-containing ACE2 treatment attenuated monocrotaline (MCT)-induced pulmonary hypertension with a reduction in pro-inflammatory cytokines in MCT-exposed mice. The finding was corroborated by an earlier finding, suggesting the positive modulatory role of ACE2 in patients with lung fibrosis [45]. To confirm this finding, Shenoy et al. [46] reported the therapeutic efficacy of ACE2 in a rat model of pulmonary hypertension.

Apart from the regular respiratory symptoms associated with COVID-19, other pathologies affecting the heart, kidneys, and nervous system as well as metabolic disorders, such as diabetes, have also been reported, suggesting the involvement of the endothelium, thus as the target organ of coronavirus [47]. Recent meta-analyses have shown the effectiveness of RAS inhibitors in infected subjects, thereby reducing the level of hospitalization of patients with underlying chronic disease conditions, such as hypertension [48]. Overall, inhibiting the overexpression of ACE2 in hypertensive COVID-19 patients may contribute remarkably to the reduction in the incidence of hospitalization, morbidity, and overall mortality in the current COVID-19 pandemic [49].

\section{ACE2 and Chronic Kidney Disease (CKD)}

In the kidneys, the ACE2 levels were high in the proximal tubular epithelial cells and endothelial cells of the renal tissue, in contrast with the glomerular cells that had low levels [50]. However, it was observed that the kidneys in healthy and disease states did not exhibit a dichotomy in the ACE2 expression in human subjects [51]. In contrast, ACE2 and ACE in rat kidneys have been found to be localized only in proximal tubules [52]. Furthermore, metabolic disorders and kidney disease have been associated with diminished ACE2 occurrence [53]. Low ACE2 vascular expression has been shown to aggravate vascular and renal diseases in recovering patients [54].

Recent studies have demonstrated that kidney impairment is commonly associated with COVID [55]. Therefore, the monitoring of sodium intake is recommended during severe COVID19 infections, especially in patients with preexisting comorbidities [56]. Of note, end-stage kidney disease was observed in a COVID-19-infected 
septuagenarian [57]. Similarly, $\sim 10 \%$ of COVID-19infected patients could develop acute kidney injury (AKI) with poor prognosis and grave sequelae. It has been reported that COVID-19 patients with AKI tend to have a poor prognosis, accompanied by proteinuria and/or microhematuria due to the integration of the COVID-19 virus into the host cells [58]. Fulminating AKI in young patients with COVID infection has been reported [55]. The light and electron microscopic tissue examination of COVID-19 hospitalized patients revealed injuries to kidney tubules, necrosis, and the appearance of coronavirus-like particles in renal tubular epithelial cells, thus necessitating renal function monitoring in COVID-19 patients [59].

\section{ACE2 and Atherosclerosis}

Hypertension, renal disease, and pulmonary injury are common comorbidities in COVID-19 infection. However, evidence has shown the involvement of the RAS in modifying the pathophysiology of atherosclerotic plaque deposition on vascular wall [60]. In some reports, Ang II has been reported to directly and indirectly stimulate the pathogenic processes associated with atherosclerotic plaque deposition, and ACE2 could be used as a molecular target for modifying disease outcomes in atherosclerotic patients $[61,62]$. In another study, ACE2 overexpression was shown to attenuate atherosclerotic plaque deposition in rabbits [63]. Likewise, the anti-atherosclerotic effect of ACE2 was demonstrated in ACE2 genetically deficient mice, probably due to reduced Ang II formation [64]. Moreover, COVID-19 infection has been shown to predispose patients to thrombotic disease, probably due to the aggravation of pro-inflammatory mechanisms, known as cytokine storm [65]. Therefore, the anti-inflammatory properties of ACE2 could be used to attenuate arteriosclerotic plaque formation in COVID-19 patients.

\section{Potential Therapeutic Target of ACE2}

The current COVID-19 pandemic has brought economic hardship, created an unprecedented global burden, and affected the economies, educational sector, tourism, industry, and family life of people in developed, developing, and underdeveloped nations of the world. Since most organs, such as the lungs, hearts, and kidneys, compromised in COVID19 patients are also enriched with ACE2, blocking the overexpression of ACE2 in these organs could serve as a novel therapeutic target in effectively treating COVID-19. Furthermore, urgent research is needed to identify potential drugs that could inhibit ACE2 and mitigate lung injury in COVID-19 infections. Hence, rigorous and intensive studies in blocking the expression of ACE2 should be performed, which might help eliminate, alleviate, or reverse the overall incidence of morbidity of COVID-19 patients, especially those with severe underlying medical conditions.
Table-1: Some potential drug candidates acting against the SARS-CoV-2 [72]

\begin{tabular}{|c|c|c|}
\hline S. No. & Drug candidates & Mechanism of action \\
\hline 1 & Remdesivir & $\begin{array}{l}\text { Nucleotide analog; Broad } \\
\text { spectrum: Many viral } \\
\text { infections, inhibits } \\
\text { viral RNA synthesis }\end{array}$ \\
\hline 2 & SiRNA & $\begin{array}{l}\text { Short chains of dsRNA that } \\
\text { interferes with the expression } \\
\text { of SARS-CoV proteins }\end{array}$ \\
\hline 3 & Camostat Mesylate & $\begin{array}{l}\text { TMPRSS2 inhibitor that blocks } \\
\text { the transmembrane protease, } \\
\text { serine } 2 \text { (TMPRSS2) entry } \\
\text { pathway }\end{array}$ \\
\hline 4 & GRL0617 & Inhibits PLpro activity \\
\hline 5 & Lj001 and JL103 & $\begin{array}{l}\text { Induces accessory proteins } \\
\text { membrane damage }\end{array}$ \\
\hline 6 & Chloroquine & $\begin{array}{l}\text { An antimalarial that sequesters } \\
\text { protons in lysosomes to } \\
\text { increase the intracellular } \mathrm{pH}\end{array}$ \\
\hline 7 & Lopinavir & Inhibits PLpro (3CLpro) activity \\
\hline 8 & Pj34 & Impairs viral replication \\
\hline
\end{tabular}

Recent advances in therapeutic strategies in the treatment and management of COVID-19 included the use of BIO101 (20-hydroxyecdysone, a Mas receptor activator) as a new treatment option for managing patients with SARS-CoV-2 infection at the severe stage [66]. BIO101, a 97\% pharmaceutical grade 20-hydroxyecdysone, has demonstrated anti-inflammatory, antithrombotic, and antifibrotic properties by enhancing respiratory function and ultimately promoting survival in COVID-19 patients. Recently, a humanized decoy antibody (ACE2-Fc fusion protein) was designed to specifically abrogate virus replication by blocking the entry of the SARS-CoV-2 spike expressing pseudotyped virus into both ACE2 expressing lung cells and lung organoids [67]. Other intervention strategies against the new coronavirus have been reported for the development of therapies and vaccines against the new coronavirus variants [68-71]. Some potential drug candidates acting against the SARS-CoV-2 have also been reported (Table-1) [72]. These drugs have a novel capacity to reduce COVID-19 morbidity and mortality.

\section{Conclusion}

Further in-depth research on the potential drugs that can serve as activators of ACE2 is needed. Recent epidemiological studies have shown that severe respiratory distress syndrome and lung injury are common symptoms of COVID-19 infection. Interestingly, since the lungs are enriched with ACE2, more research on ACE2 activation is urgently needed to improve the treatment strategies for COVID-19. Previous evidence has shown that ACE2 offered protection against lung injury and pulmonary hypertension. Furthermore, we believe that the beneficial properties of the novel ACE2 should be investigated to effectively contain COVID-19. 


\section{Authors' Contributions}

AAO: Conceptualized the review. AAO, YGA, TOA, ITG, ADAA, AOA, OAA, TOO, OOF, TOO, ET, BSO, FOH, IOO,OEO, ABS, AAA, SMN, LJM, PNK, OOO, and MAY: Drafted, proof-read, and edited the manuscript. AAO and TOA: Performed language and plagiarism checks. All authors read and approved the final manuscript.

\section{Acknowledgments}

All the authors acknowledge the financial support of Cape Peninsula University of Technology, Department of Biomedical Sciences, Faculty of Health and Wellness Sciences, Bellville 7535, South Africa with grant number CPUT RJ23.

\section{Competing Interests}

The authors declare that they have no competing interests.

\section{Publisher's Note}

Veterinary World remains neutral with regard to jurisdictional claims in published institutional affiliation.

\section{References}

1. Lu, H., Cassis, L., Kooi, C.W.V. and Daugherty, A. (2016) Structure and functions of angiotensinogen. Hypertens. Res., 39(7): 492-500.

2. Wu, C., Lu, H., Cassis, L.A. and Daugherty, A. (2011) Molecular and pathophysiological features of angiotensinogen: A mini-review. N. Am. J. Med. Sci., 4(4): 183-190.

3. Singh, K.D. and Karnik, S.S. (2016) Angiotensin receptors: Structure, function, signaling and clinical applications. $J$. Cell Signal., 1(2): 111.

4. Lu, H., Balakrishnan, A., Howatt, D.A., Wu, C., Charnigo, R., Liau, G., Cassis, L.A. and Daugherty, A. (2012) Comparative effects of different modes of renin-angiotensin system inhibition on hypercholesterolaemia-induced atherosclerosis. Br. J. Pharmacol., 165(6): 2000-2008.

5. Rateri, D.L., Moorleghen, J.J., Balakrishnan, A., Owens, A.P., Howatt, D.A., Subramanian, V., Poduri, A., Charnigo, R., Cassis, L.A. and Daugherty, A. (2011) Endothelial cell-specific deficiency of Ang II Type 1a receptors attenuates Ang II-induced ascending aortic aneurysms in LDL receptor-/-mice. Circ. Res., 108(5): 574-581.

6. Portela, V.M., Castilho, A.C., Bertolin, K., Buratini, J. Jr and Price, C.A. (2016) Localization of angiotensin receptor Type 2 in fetal bovine ovaries. Anim. Reprod. Sci., 168: 34-39.

7. Donoghue, M., Hsieh, F., Baronas, E., Godbout, K., Gosselin, M., Stagliano, N., Donovan, M., Woolf, B., Robison, K., Jeyaseelan, R., Breitbart, R.E. and Acton, S. (2000) A novel angiotensin-converting enzyme-related carboxypeptidase (ACE2) converts angiotensin I to angiotensin 1-9. Circ. Res., 87(5): 1E-9.

8. Tipnis, S.R., Hooper, N.M., Hyde, R., Karran, E., Christie, G. and Turner, A.J. (2000) A human homolog of angiotensin-converting enzyme. Cloning and functional expression as a captopril-insensitive carboxypeptidase. $J$. Biol. Chem., 275(43): 33238-33243

9. Patel, S., Rauf, A., Khan, H. and Abu-Izneid, T. (2017) Renin-angiotensin-aldosterone (RAAS): The ubiquitous system for homeostasis and pathologies. Biomed. Pharmacother., 94: 317-325.
10. Kuba, K., Imai, Y., Ohto-Nakanishi, T. and Penninger, J.M. (2010) Trilogy of ACE2: A peptidase in the therenin-angiotensin system, a SARS receptor, and a partner for amino acid transporters. Pharmacol. Ther., 128(1): 119-128.

11. Hamming, M.E., Cooper, M.E., Haagmans, B.L., Hooper, N.M., Korstanje, R., Osterhaus, A.D.M., Timens, W., Turner, A.J., Navis, G. and van Goor, H. (2007) The emerging role of ACE2 in physiology and disease. $J$. Pathol., 212(1): 1-11.

12. Vaughan, E.D. and Peach, M.J. (1974) Letter: Regulation of aldosterone biosynthesis by "angiotensin III." N. Engl. J. Med., 291(22): 1193.

13. Campagnole-Santos, M.J., Diz, D.I., Santos, R.A., Khosla, M.C., Brosnihan, K.B. and Ferrario, C.M. (1989) Cardiovascular effects of angiotensin-(1-7) injected into the dorsal medulla of rats. J. Physiol. Heart Circ. Physiol., 257(1-2): H324-H329.

14. Santos, R.A., Brosnihan, K.B., Chappell, M.C., Pesquero, J., Chernicky, C.L., Greene, L.J. and Ferrario, C.M. (1988) Converting enzyme activity and angiotensin metabolism in the dog brainstem. Hypertension, 11(2): I153-I157.

15. Shete, A. (2020) Urgent need for evaluating agonists of angiotensin-(1-7)/Mas receptor axis for treatment of patients with COVID-19. Int. J. Infect. Dis., 96(2020): 348-351.

16. Burrell, L.M., Johnston, C.I., Tikellis, C. and Cooper, M.E. (2004) ACE2, a new regulator of the renin-angiotensin system. Trends Endocrinol. Metab., 15(4): 166-169.

17. Nakhleh, A. and Shehadeh, A. (2020) Interactions between antihyperglycemic drugs and the renin-angiotensin system: Putative roles in COVID-19. A mini-review. Diabetes Metab. Syndr., 14(14): 509-512.

18. Devaux, C.A. (2020) ACE2 receptor polymorphism: Susceptibility to SARS-CoV-2, hypertension, multi-organ failure, and COVID-19 disease outcome. J. Microbiol. Immunol. Infect., 53(3): 425-435.

19. Young, D., Waitches, G., Birchmeier, C., Fasano, O. and Wigler, M. (1986) Isolation and characterization of a new cellular oncogene encoding a protein with multiple potential transmembrane domains. Cell, 45(5): 711-719.

20. Santos, R.A., Simoes e Silva, A.C., Maric, C., Silva, D.M.R., Machado, R.P., de Buhr, I., Heringer-Walther, S., Pinheiro, S.V.B., Lopes, M.T., Bader, M., Mendes, E.P., Lemos, V.S., Campagnole-Santos, M.J., Schultheiss, H.P., Speth, R. and Walther, T. (2003) Angiotensin-(1-7) is an endogenous ligand for the $\mathrm{G}$ protein-coupled receptor Mas. Proc. Natl. Acad. Sci. U. S. A., 100(14): 8258-8263.

21. Jackson, T.R., Blair, L.A., Marshall, J., Goedert, M. and Hanley, M.R. (1988) The mas oncogene encodes an angiotensin receptor. Nature, 335(6189): 437-440.

22. South, A.M., Shaltout, H.A., Washburn, L.K., Hendricks, A.S., Diz, D.I. and Chappell, M.C. (2019) Fetal Programming and the angiotensin-(1-7) Axis: A review of the experimental and clinical data. Clin. Sci., 133(1): 55-74.

23. Nunes-Silva, A., Rocha, G.C., Magalhaes, D.M., Vaz, L.V., de Faria, M.H.S. and Silva, A.C.M. (2017) Physical exercise and ACE2-angiotensin-(1-7)-mas receptor axis of the renin-angiotensin system protein. Pept Lett., 24(9): 809-816.

24. Prestes, T.R.R., Rocha, N.P., Miranda, A.S., Teixeira, A.L. and Simoes-E-Silva, A.C. (2017) The anti-inflammatory potential of ACE2/angiotensin-(1-7)/mas receptor axis: Evidence from basic and clinical research. Curr. Drug Targets., 18(11): 1301-1313.

25. Durand, M.J., Zinkevich, N.S., Riedel, M., Gutterman, D.D., Nasci, V.L., Salato, V.K., Hijjawi, J.B., Reuben, C.F., North, P.E. and Beyer, A.M. (2016) Vascular actions of angiotensin 1-7 in the human microcirculation: Novel role for telomerase. Arterioscler. Thromb. Vasc. Biol., 36(6): 1254-1262.

26. Kuba, K., Imai, Y., Rao, S., Gao, H., Guo, F., Guan, B., Huan, Y., Yang, P., Zhang, Y., Deng, W., Bao, L., Zhang, B., Liu, G., Wang, Z., Chappell, M., Liu, Y., Zheng, D., 
Leibbrandt, A., Wada, T., Slutsky, A.S., Liu, D., Qin, C., Jiang, C. and Penninger, J.M. (2005) A crucial role of angiotensin-converting enzyme 2 (ACE2) in SARS coronavirus-induced lung injury. Nat. Med., 11(8): 875-879.

27. Aleksova, A., Ferro, F., Gagno, G., Cappelletto, C., Santon, D., Rossi, M., Ippolito, G., Zumla, A., Beltrami, A.P. and Sinagra, P. (2020) COVID-19 and renin-angiotensin system inhibition-role of angiotensin-converting enzyme 2 (ACE2)-is there any scientific evidence for controversy? $J$. Intern. Med., 288(4): 410-421.

28. Guan, W.J., Ni, Z.Y., Hu, Y., Liang, W.H., Ou, C.Q., He, J.X., Liu, L., Shan, H., Lei, C.L., Hui, D.S.C., Du, B., Li, L.J., Zeng, G., Yuen, K.Y., Chen, R.C., Tang, C., Wang, T., Chen, P.Y., Xiang, J., Li, S.Y., Wang, J.L., Liang, Z.J., Peng, Y.X., Wei, L., Liu, Y., Hu, Y.H., Peng, P., Wang, J.M., Liu, J.Y., Chen, Z., Li, G., Zheng, Z.J., Qiu, S.Q., Luo, J., Ye, C.J., Zhu, S.Y. and Zhong, N.S. (2020) Clinical characteristics of 183 coronavirus disease 2019 in China. N. Engl. J. Med., 382(18): 1708-1720.

29. Zhao, Y., Zhao, Z., Wang, Y., Zhou, Y., Ma, Y. and Zuo, W. (2020) Single-cell RNA expression profiling of ACE2, the putative receptor of Wuhan 2019-nCov. Am. J. Respir. Crit. Care Med., 202(5): 756-759.

30. Wang, D., Hu, B., Hu, C., Zhu, F., Liu, X., Zhang, J., Wang, B., Xiang, H., Cheng, Z., Xiong, Y., Zhao, Y., Li, Y., Wang, X. and Peng, Z. (2020) Clinical characteristics of 138 hospitalized patients with 2019 novel coronavirus-infected pneumonia in Wuhan, China. JAMA, 323(11): 1061-1069.

31. Patel, V.B., Zhong, J.C., Grant, M.B. and Oudit, G.Y. (2016) Role of the ACE2/angiotensin 1-7 axis of the renin-angiotensin system in heart failure. Circ. Res., 118(8): 1313-1326.

32. Tomasz, J., Mohiddin, S.A., Dimarco, A., Patel, V., Savvatis, K., Marelli-Berg, F.M., Madhur, M.S., Tomaszewski, M., Maffia, P., D’Acquisto, F., Nicklin, S.A., Marian, A.J., Nosalski, R., Murray, E.C., Guzik, B.J., Berry, C., Touyz, R.M., Kreutz, R., Wang, D.W., Bhella, D., Sagliocco, O., Crea, F., Thomson, E.C. and McInnes, I.B. (2020) COVID-19 and the cardiovascular system: Implications for risk assessment, diagnosis, and treatment options. Cardiovasc. Res., 116(10): 1666-1687.

33. Kuba, K., Imai, Y., Penninger, J.M. (2006). Angiotensinconverting enzyme 2 in lung diseases. Curr. Opin. Pharmacol.,6(3):271-6.

34. Cheng, Y., Luo, R., Wang, K., Zhang, M., Wang, Z., Dong, L., Li, J., Yao, Y., Ge, S. and Xu G. (2020) Kidney disease is associated with in-hospital death of patients with COVID-19. Kidney Int., 97(5): 829-838.

35. Zhang, J., Dong, J., Martin, M., He, M., Gongol, B., Marin, T.L., Chen, L., Shi, X., Yin, Y., Shang, F., Wu, Y., Huang, H.Y., Zhang, J., Zhang, Y., Kang, J., Moya, E.A., Huang, H.D., Powell, F.L., Chen, Z., Thistlethwaite, P.A., Yuan, Z.Y. and Shyy, J.Y.J. (2018) AMP-activated protein kinase phosphorylation of angiotensin-converting enzyme 2 in endothelium mitigates pulmonary hypertension. Am. $J$. Respir. Crit. Care Med., 198(4): 509-520.

36. Liu, Z., Huang, X.R., Chen, H.Y., Penninger, J.M. and Lan, H.Y. (2012) Loss of angiotensin-converting enzyme 2 enhances TGF-beta/smad-mediated renal fibrosis and NF-kappa BY driven renal inflammation in a mouse model of obstructive nephropathy. Lab. Invest., 92(5): 650-661.

37. Yamazato, Y., Ferreira, A.J., Hong, K.H., Sriramula, S., Francis, J., Yamazato, M., Yuan, L., Bradford, C.N., Shenoy, V., Oh, S.P., Katovich, M.J. and Raizada, M.K (2009) prevention of pulmonary hypertension by angiotensin-converting enzyme 2 gene transfer. Hypertension, 54(2): 365-371.

38. Shenoy, V., Ferreira, A.J., Qi, Y., Fraga-Silva, R.A., DíezFreire, C., Dooies, A., Jun, J.Y., Sriramula, S., Mariappan, N., Pourang, D., Venugopal, C.S., Francis, J., Reudelhuber, T., Santos, R.A., Patel, J.M., Raizada, M.K. and Katovich, M.J. (2010) The angiotensin-converting enzyme 2/angiogenesis-(1-7)/mas axis confers cardiopulmonary protection against lung fibrosis and pulmonary hypertension. Am. J. Respir. Crit. Care Med., 182(8): 1065-1072.

39. Shenoy, V., Kwon, K.C., Rathinasabapathy, A., Lin, S., Jin, G., Song, C., Shil, P., Nair, A., Qi, Y., Li, Q., Francis, J., Katovich, M.J., Daniell, H. and Raizada, M.K. (2014) Oral delivery of angiotensin-converting enzyme 2 and angiotensin-(1-7) bioencapsulated in plant cells attenuates pulmonary hypertension. Hypertension, 64(6): 1248-1259.

40. Sardu, C., Gambardella, J., Morelli, M.B., Wang, X., Marfella, R. and Santulli, G. (2020) Hypertension, thrombosis, kidney failure, and diabetes: Is COVID-19 an endothelial disease? A comprehensive evaluation of clinical and basic evidence. J. Clin Med., 9(5): 1417.

41. Guo, X., Zhu, Y. and Hong, Y. (2020) Decreased mortality of COVID-19 with renin-angiotensin-aldosterone system inhibitors therapy in patients with hypertension: A meta-analysis. Hypertension, 76(2): e13-e14.

42. Zhong, J.C., Ye, J.Y., Jin, H.Y., Yu, X., Yu, H.M., Zhu, D.L., Gao, P.J., Huang, D.Y., Shuster, M., Loibner, H., Guo, J.M., Yu, X.Y., Xiao, B.X., Gong, Z.H., Penninger, J.M. and Oudit, G.Y. (2011) Telmisartan attenuates aortic hypertrophy in hypertensive rats by the modulation of ACE2 and profilin-1 expression. Regul. Pept., 166(1-3): 90-97.

43. Goru, S.K., Kadakol, A., Malek, V., Pandey, A., Sharma, N. and Gaikwad, A.B. (2017) Diminazene aceturate prevents nephropathy by increasing glomerular ACE2 and AT(2) receptor expression in a rat model of Type 1 diabetes. $B r . J$. Pharmacol., 174(18): 3118-3130.

44. Yamazato, Y., Ferreira, A.J., Hong, K.H., Sriramula, S., Francis, J., Yamazato, M., Yuan, L., Bradford, C.N., Shenoy, V., Oh, S.P., Katovich, M.J. and Raizada, M.K. Prevention of pulmonary hypertension by Angiotensinconverting enzyme 2 gene transfer. Hypertension, 54(2):365-71.

45. Tikellis, C., Johnston, C.I., Forbes, J.M., Burns, W.C., Burrell, L.M., Risvanis, J. and Cooper, M.E. (2003) Characterization of renal angiotensin-converting enzyme 2 in diabetic nephropathy. Hypertension, 41(3): 392-397.

46. Shenoy, V., Qi, Y., Katovich, M.J., Raizada, M.K. (2011). ACE2, a promising therapeutic target for pulmonary hypertension. Curr. Opin. Pharmacol., 11(2):150-5.

47. Tikoo, K., Patel, G., Kumar, S., Karpe, P.A., Sanghavi, M., Malek, V. and Srinivasan, K. (2015) Tissue-specific up regulation of ACE2 in rabbit model of atherosclerosis by atorvastatin: Role of epigenetic histone modifications. Biochem. Pharmacol., 93(3): 343-351.

48. Post, A., Dullaart, R.P.F. and Bakker, S.J.L. (2020) Sodium status and kidney involvement during COVID-19 infection. Virus Res., 286(2020): 198034.

49. Yamada, T., Mikami, T., Chopra, N., Miyashita, H., Chernyavsky, S. and Miyashita, S. (2020) Patients with chronic kidney disease have a poorer prognosis of coronavirus disease 2019 (COVID-19): An experience in New York City. Int. Urol. Nephrol., 52(7): 1405-1406.

50. Dian, F., Yang, B., Xu, J., Mao, Z., Zhou, C. and Xue, C. (2020) COVID-19 infection in a patient with end-stage kidney disease. Nephron, 144(5): 245-247.

51. Zhang, J., Wu, J., Sun, X., Xue, H., Shao, J., Cai, W., Jing, Y., Yue, M. and Dong, C. (2020) Associations of hypertension with the severity and fatality of SARS-CoV-2 infection: A meta-analysis. Epidemiol. Infect., 148 (2020): e106.

52. Zhang, F. and Liang, Y. (2020) Potential risk of the kidney vulnerable to novel coronavirus 2019 infection. Am. J. Physiol. Ren. Physiol., 318(5): F1136-F1137.

53. Lai, C., Ko, W.C., Lee, P.I., Jean, S.S. and Hsueh, P.R. (2020) Extra-respiratory Manifestations of COVID-19. Int. J. Antimicrob. Agents, 56(2): 106024.

54. Angel-Korman, A., Brosh, T., Glick, K. and Leiba, A. (2020) Covid-19, the kidney and hypertension. Harefuah, 159(4): 231-234.

55. Gopalakrishnan, A., Mossaid, A., Lo, K.B., Vasudevan, A., 
McCullough, P.A. and Rangaswami, J. (2020) Fulminant acute kidney injury in a young patient with novel coronavirus 2019. Cardiorenal Med., 10(4): 217-222.

56. Su, H., Wan, C., Yi, L.X., Tang, F., Zhu, H.Y., Yi, F., Yang, H.C., Fogo, A.B., Nie, X. and Zhang, C. (2020) Renal histopathological analysis of 26 postmortem findings of patients with COVID-19 in China. Kidney Int., 98(1): 219-227.

57. Carratalá, V.P., Górriz-Zambrano, C., Ariño, C.M., Caro, J.L.L. and Gorriz, J.L. (2020) COVID-19 and cardiovascular and kidney disease: Where are we? Where are we going? Semergen, 46(1): 78-87.

58. Nguyen, D. and Touyz, R.M. (2011) A new look at the renin-angiotensin system focusing on the vascular system. Peptides, 32(10): 2141-2150.

59. Hirata, Y., Fukuda, D. and Sata, M. (2011) Critical role of renin-angiotensin system in the pathogenesis of atherosclerosis. Nihon Rinsho., 69(1): 55-59.

60. Chrysant, S.G., Chrysant, G.S., Chrysant, C. and Shiraz, M. (2010) The treatment of cardiovascular disease continuum: Focus on prevention and RAS blockade. Curr. Clin. Pharmacol., 5(2): 89-95.

61. Wang, Y., Tikellis, C., Thomas, M.C. and Golledge, J. (2013) Angiotensin-converting enzyme 2 and atherosclerosis. Atherosclerosis, 226(1): 3-8.

62. Zhang, C., Zhao, Y.X., Zhang, Y.H., Zhu, L., Deng, B.P., Zhou, X.L., Li, S.Y., Lu, Z.T., Song, L.L., Lei, X.M., Tang, W.B., Wang, N., Pan, C.M., Song, H.D., Liu, C.X., Dong, B., Zhang, Y. and Cao, Y. (2010) Angiotensinconverting enzyme 2 attenuates atherosclerotic lesions by targeting vascular cells. Proc. Natl. Acad. Sci., 107(36): 15886-15891.

63. Sahara, M., Ikutomi, M., Morita, T., Minami, Y., Nakajima, T., Hirata, Y., Nagai, R. and Sata, M. (2014) Deletion of angiotensin-converting enzyme 2 promotes the development of atherosclerosis and arterial neointima formation. Cardiovasc. Res., 101(2): 236-246.

64. Tikellis, C., Bernardi, S. and Burns, W.C. (2011) Angiotensin-converting enzyme 2 is a key modulator of the renin-angiotensin system in cardiovascular and renal disease. Curr. Opin. Nephrol. Hypertens., 20(1): 62-68.

65. Bikdeli, B., Madhavan, M.V., Jimenez, D., Chuich, T., Dreyfus, I., Driggin, E., Der Nigoghossian, C., Ageno, W., Madjid, M., Guo, Y., Tang, L.V., Hu, Y., Giri, J.,
Cushman, M., Quéré, I., Dimakakos, E.P., Gibson, C.M., Lippi, G., Favaloro, E.J., Fareed, J., Caprini, J.A., Tafur, A.J., Burton, J.R., Francese, D.P., Wang, E.Y., Falanga, A., McLintock, C., Hunt, B.J., Spyropoulos, A.C., Barnes, G.D., Eikelboom, J.W., Weinberg, I., Schulman, S., Carrier, M., Piazza, G., Beckman, J.A., Steg, P.G., Stone, G.W., Rosenkranz, S., Goldhaber, S.Z., Parikh, S.A., Monreal, M., Krumholz, H.M., Konstantinides, S.V., Weitz, J.I. and Lip. G.Y.H. (2020) 39COVID-19 and thrombotic or thromboembolic disease: Implications for prevention, antithrombotic therapy, and follow-up. J. Am. Coll. Cardiol., 75(23): 2950-2973.

66. Dioh, W., Chabane, M., Tourette, C., Azbekyan, A., Morelot-Panzini, C., Hajjar, L.A., Lins, M., Nair, G.B., Whitehouse, T., Mariani, J., Latil, M., Camelo, S., Lafont, R., Dilda, P.J., Veillet, S. and Agus, S. (2021) Testing the efficacy and safety of BIO101, for the prevention of respiratory deterioration, in patients with COVID-19 pneumonia (COVA study): A structured summary of a study protocol for a randomised controlled trial. Trials, 22(1): 42.

67. Huang, K.Y., Lin, M.S., Kuo, T.S., Chen, C.L., Lin, C.C., Chou, Y.C., Chao, T.L., Pang, Y.H., Kao, H.C., Huang, R.S.S., Lin, S., Chang, S.Y. and Yang, P.S. (2021) Humanized COVID-19 decoy antibody effectively blocks viral entry and prevents SARS-CoV-2 infection. EMBO Mol. Med., 13(1): e12828.

68. Papageorgiou, A.C. and Mohsin, I. (2020) The SARSCoV-2 spike glycoprotein as a drug and vaccine target: Structural insights into its complexes with ACE2 and antibodies. Cells, 9(11): 2343.

69. Gheblawi, M., Wang, K., Viveiros, A., Nguyen, O., Zhong, J.C., Turner, A.J., Raizada, M.K., Grant, M.B. and Oudit, G.Y. (2020) Angiotensin-converting enzyme 2: SARS-CoV-2 receptor and regulator of the renin-angiotensin system: Celebrating the $20^{\text {th }}$ anniversary of the discovery of ACE2. Circ. Res., 126(10): 1456-1474.

70. Jia, H., Neptune, E. and Cui, H. (2021) Targeting ACE2 for COVID-19 therapy: Opportunities and challenges. Am. J. Respir. Cell Mol. Biol., 64(4): 416-425.

71. Shagufta, A.I. (2021) The race to treat COVID-19: Potential therapeutic agents for the prevention and treatment of SARS-CoV-2. Eur. J. Med. Chem., 213(2021): 113157.

72. Saxena, A. (2020) Drug targets for COVID-19 therapeutics: Ongoing global efforts. J. Biosci., 45(1): 87. 